\title{
Types of knowledge in science-based practices
}

\section{Nelius Boshoff}

\begin{abstract}
Science communication as an interdisciplinary field of study has always been concerned with issues of knowledge utilisation. This theoretical paper focusses on the "knowledge" part of knowledge utilisation and provides a conceptual frame to distinguish between different types of knowledge in science-based practice. A practitioner's knowledge store is portrayed as a dense set of personal knowledge, consisting of procedural knowledge, factual knowledge, potential factual knowledge and opinions/beliefs; the totality of which is continuously refined through more experiences and additional information received from people, documents or events. Implications for future studies of knowledge utilisation in science-based practices are highlighted and a number of questions posed to science communication as a profession.
\end{abstract}

KEYWORDS: Expert, knowledge, tacit, utilisation

\section{Introduction}

Historically, there has been a close association between "science communication" and "knowledge utilisation" as academic fields. An example is the history of the journal Science Communication. The journal originally began in 1979 as Knowledge: Creation, Dissemination, Utilization, before changing to its current title (Science Communication) in 1995. However, more recently the historical link between the fields of science communication and knowledge utilisation has become quite tenuous. This is evident from the small number of articles on the topic published since 2000 in both Science Communication [1-7] and JCOM [8-10] (although the latter journal only started in 2002).

The notion of "knowledge utilisation" implies two interrelated concepts - "knowledge" and "utilisation" - and both of these deserve to be the subject of scholarly investigation. So far, though, it seems as if the emphasis in science communication has been more on studies of utilisation and pathways to utilisation, rather than on deepening the understanding of what is meant by knowledge, the different types of knowledge in different contexts, and how these could either facilitate or prevent the communication and uptake of scientific research findings. A notable exception is a paper by Jacobson [3] that appeared in Science Communication in 2007. The subtext of Jacobson's discussion is that the knowledge part of knowledge utilisation has been neglected and that social epistemology, or the theory of the social aspects and dynamics of knowledge, could be useful in that regard. According to Jacobson: 
research in knowledge transfer and exchange has generally been more focused on using theory to explain, plan, or research transfer and exchange processes than on using it to understand knowledge and the relationships between knowledge and these processes [3, p. 120].

It is against this backdrop - of a lack of theorization about the meaning and dynamics of knowledge in studies of knowledge utilisation - that my paper is aiming to make a contribution. The paper provides a theoretical framework for distinguishing between various types of knowledge in practice, which could inform future studies on the social dynamics of knowledge in the uptake of research findings in practice. The goal is to stimulate enquiry into studies of different types of knowledge in different contexts of practice as an area of research for academics who work at the intersection of science communication and knowledge utilisation. The context in which I will be discussing the different types is science-based practice, from the perspective of the "practitioners" who operate in that context.

Practitioners of science-based practises include two categories of professionals: firstly, those whose activities are informed by the outputs of science (e.g. doctors, nurses and winemakers) and secondly, those whose task it is to produce science (e.g. molecular biologists). Explicit demands for evidence-based practice (EBP) are almost non-existent in the case of the second category of professionals; most probably because it is assumed that scientists would automatically update their scientific knowledge as part of doing research. Peer review of scientific publications, for instance, could act as a mechanism to ensure that those who produce science are also conversant with the latest global scientific developments as it is commonly expected of them to contextualise their research within the global scientific literature. However, of all science-based practitioners the call for EBP is most strongly felt in the case of health practitioners, who belong to the first category of professionals. This is no surprise as the decisions taken by health practitioners often deal with matters of life or death. Between these two extremes - of no explicit pressures for EBP and, on the other hand, well-articulated and strongly felt pressures for EBP all other science-based practitioners are to be located (i.e. winemakers, veterinarians and social workers, to mention a few others).

Practitioners in science-based practises therefore refer to a diverse group of professionals who share a number of characteristics. Firstly, all received their initial training at some institution of higher learning, where they were exposed to the best of scientific information available at the time. Secondly, in the execution of their respective professions it is expected of them, either explicitly or implicitly, to be continuously aware of the latest scientific and research developments in their fields, and to make use of the various tools and mechanisms that were specifically developed for that purpose (e.g. practice guidelines, workshops, research synopses). Thirdly, not being conversant with the latest scientific and research developments could have detrimental consequences - not only for the practitioners and their immediate clientele/beneficiaries, but also for society at large. Examples of negative consequences on a larger scale could include preventable mortality and health systems that are cost-ineffective (for health practitioners), lack of industrial 
innovation and economic non-competitiveness (for winemakers in "new world" wine industries) and an inadequate human capital base (for university researchers responsible for producing the next generation of scientists).

Although some may argue that discussions of the meaning of knowledge in different contexts of practice - in this case science-based practice - are too far removed from the field of science communication, others may argue that such a statement itself is estranged from reality. In a recent contribution to JCOM, the current editor of Science Communication, Susanna Priest, underscores the need for scholars of science communication to move beyond the conventional demarcations of the field by stating that:

we have learned over the years that science communication is not just a translation problem - not, in other words, a simple matter of using familiar words to convey complex subject matter, nor even a matter of communicating a particular set of facts or ideas more accurately. Rather, it is something more subtle that invokes questions about a host of profound philosophical issues such as what is scientific truth, as well as sociological ones such as whose truth most matters in society [11, p. 2].

In this paper I focus on the different "truths" of science-based practitioners, where these are portrayed as different types of knowledge in practice. Science-based practitioners such as doctors or nurses do not accept new knowledge (whether scientific or not) unconditionally, but first "make decisions about the value, usefulness, and appropriateness of particular knowledge to their setting and circumstances" [12, p. 20]. A practitioner's existing knowledge thus acts as either a barrier or facilitator in the uptake of new knowledge. Against this backdrop it seems worthwhile to unpack the key elements of what I call a practitioner's personal knowledge store, which includes both factual and procedural knowledge.

The paper starts with a discussion of these different types of knowledge and moves towards constructing a visual representation of a practitioner's knowledge store. This is followed by a brief discussion that links the concept of a practitioner's knowledge store with the notions of "mindlines" and "knowledge networks", which were developed by others. Insights from the different types of knowledge are also used to reflect on whether science-based practitioners prioritize non-scientific knowledge over scientific knowledge. In conclusion I briefly outline the implications of the theoretical framework for future studies of knowledge utilisation being conducted as part of science communication as an interdisciplinary field of study. I also pose a number of questions about science communication as a field of professional specialisation.

\section{The different types of knowledge}

The distinction between "know-that" and "know-how", which was made by the philosopher Gilbert Ryle [13, 14], highlights two types of knowledge in practice: knowing that something is the case and knowing how to do things. Sahdra and Thagard [15], for instance, who studied the practices of molecular biologists, concluded that the knowledge 
of these scientists not only consists of facts about cellular molecules or theories of the workings of molecules, but also of ways of doing things practically in the laboratory. The two knowledge types go by different names in the scientific literature. "Know-that" is sometimes referred to as factual knowledge, propositional knowledge, theoretical knowledge, explicit knowledge or declarative knowledge. Similarly, a number of terms are used to refer to "know-how" or aspects thereof, including procedural knowledge, practical knowledge, implicit knowledge, experiential knowledge and tacit abilities and skills. In this paper, the terms factual knowledge and procedural knowledge are used together with "know-that" and "know-how". The purpose is to unpack these terms with reference to the relevant literature and to combine the insights in a visual representation of a practitioner's knowledge store.

\section{Unpacking factual knowledge}

The conventional conception of factual knowledge is that it is justified, true belief. Factual knowledge is normally expressed as a proposition, or is able to be expressed as a proposition, even if the knowledge is never vocalized but only passes through the head as a statement [16]. Moreover, factual knowledge is "formal, explicit, derived from research and scholarship and concerned with generalizability" [17, p. 83], meaning that the propositions have been empirically derived through systematic observation and experimentation [18]. Scientific evidence, therefore, can justify a belief as a factual claim, because the evidence is empirical, replicable, verifiable and public.

However, science is accumulative as new knowledge is constantly generated that supports, contests or even supersedes existing knowledge; scientific theories also shift within larger paradigms. Scientific evidence thus represents the best of current evidence at a particular point in time and does not provide absolute and unconditional justification. In other words, the degree to which a person is justified in believing that something is the case at time $\mathrm{X}$, depends on how well developed and credible the scientific evidence base for that belief is at time X. According to Haack [19, p. 81] "justification comes in degrees" and scientific evidence can be interpreted as a relevant source of justification for a certain belief on the basis of other background beliefs, which may or may not be true.

Scientific research generates factual claims but the attention of research obviously cannot be devoted to each and every conceivable concern. One could therefore argue that certain claims may very well have a potential scientific base but the research to demonstrate their "factuality" has not yet been conducted or, where the research does exist, has not explicitly and deliberately been linked to that belief. Thus, some beliefs and opinions fall in a grey zone, as the verdict concerning their factuality can only be determined through systematic research and scholarship. In the absence of supporting scientific research evidence, a belief maintains its pervasiveness and pseudo-factuality through colloquial evidence. Colloquial evidence, according to the definition by the Canadian Health Services Research Foundation, is "anything that establishes a fact or gives reason for believing in something" [20, p. 3]. These include, among others, evidence about resources, expert and 
professional opinion, judgement, values, habits and traditions, as well as the particular pragmatics and contingencies of the situation. For that reason the notion of "potential factual knowledge" can be used to indicate beliefs and opinions where the claims have not yet been verified through the scientific method.

To summarise, the common factor between factual knowledge, potential factual knowledge and ordinary beliefs is that all involve claims that can easily be codified. However, the three sets of claims differ in terms of the degree of their supporting scientific evidence. Whereas factual knowledge has a known scientific backing, ordinary beliefs have none. Potential factual knowledge sits somewhere in-between as a special category of belief that may or may not be "upgraded" to factual knowledge once the relevant claim has been subjected to the scientific method.

\section{Unpacking procedural knowledge}

Procedural knowledge refers to skills and abilities that are demonstrated in practice through the performance of procedures, without the performer necessarily being able to articulate what is being done. The emphasis is on "necessarily" because in some cases a skilful performer may also be able to describe the procedure. Pears [16] mentioned two examples of know-how from everyday life where the underlying factual content is present and absent respectively:

[A] cook who knows how to produce a soufflé will almost certainly be able to say how it is done, and when he does, he will be showing that he knows such facts as this: if the product is going to be a soufflé, the yolks and the whites must be separated [16, p. 26].

I know how to ride a bicycle, but I cannot say how I balance because I have no method. I may know that certain movements, and even that certain muscles are involved, but that factual knowledge comes later, if at all, and it could hardly be used in instruction, like the factual knowledge of the cook [16, p. 26].

Procedural knowledge does not always remain implicit and without conscious awareness. Thagard [21] illustrates this point with reference to three hypothetical cases about the know-how involved in scientific collaboration. The first is where the know-how is explicit from the start and a verbal rule has already been articulated. An example is an experienced scientific collaborator telling a novice that, according to best practice, one should select only collaborators with complementary strengths, and the novice then acts on this advice and eventually sees it as the main explanation for his/her own know-how of collaboration. In the second case, there is no verbal rule in place but a rule can potentially be extracted from the procedural knowledge exhibited. An example is an experienced collaborator who displays a certain kind of behaviour, such as how to run a laboratory group meeting, which is then "picked up" by the novice who stores a memory of this behaviour and eventually also duplicates it. The novice, if really pressed, could make the relevant know-how explicit by formulating one or more verbal rules for it. Lastly, 
there are instances where procedural knowledge is inherently implicit and impossible to translate into verbal rules, for instance in the case of a novice who does not have:

any conscious awareness or memory of the physical, intellectual, or social behaviours of the experienced collaborator but nevertheless encodes and eventually duplicates them [21, p. 187].

The latter quote is also an example of tacit knowledge, i.e. knowledge implicitly acquired from everyday practice and which is very difficult, if not impossible, for the bearer to articulate (Sternberg et al., cited in [22]). According to Polanyi [23], tacit knowledge involves a functional relation between two "terms": a proximal term and a distal term. In tacit knowing, one attends from the proximal to the distal, but it is the proximal term of which one possesses tacit knowledge. To use Polanyi's example, by tacitly knowing a face, one attends from the facial features (proximal) to the face (distal) without necessarily being able to specify the features responsible for the immediate recognition. Tacit knowing therefore involves the integration of the particulars (proximal) to achieve the coherent entity (distal) to which one is attending. However, the process of integration goes beyond the mere observation of the particulars. The joint meaning of the particulars is only achieved by fully incorporating the particulars within oneself.

Moreover, decisions and actions flowing from procedural knowledge often appear to lack analytical reasoning. They happen quickly and effortlessly, with the same automaticity that is typical of habitual behaviour [24], and tend to be largely intuitive. Carper [25] was one of the first to identify intuition as an important source of knowing in nursing. Also in nursing, McCormack [26] performed a concept analysis of the notion and presented four defining attributes of intuition: (i) immediate, unjustified true belief which is not preceded by inference; (ii) non-propositional knowledge which is holistic in nature; (iii) immediate knowledge of a concept that is independent of the linear reasoning process; and (iv) a form of knowing that represents synthesis rather than analysis.

Intuition, being instinctive, at times manifests as gut feelings and "common sense". Stolper et al. [27] identified two common types of gut feelings among clinical practitioners, namely a sense of alarm and a sense of reassurance. A sense of alarm involves a number of elements: an uneasy feeling that something is wrong with a patient even though the practitioner cannot find any indications objectively supporting that feeling, a distrust of the situation because the prognosis appears to be uncertain, and a need for some kind of intervention in order to avoid an adverse health problem. A sense of reassurance, on the other hand, emerges as a secure feeling, specifically when the appropriate intervention is clear in the mind of the practitioner even though a proper diagnosis could still be lacking.

Firmly embedded within the intuitive aspect of procedural knowledge is the notion of "common sense". A common sense view of matters, according to Geertz [28], means that one attributes certain quasi-qualities to reality, such as naturalness, "practicalness" and "thinness". Common sense wisdom, in practice, therefore can result in one course of action being intuitively selected above another, given that nothing needs to be queried or reflected on, as the chosen action represents the way things are (naturalness), the chosen 
action is the obvious thing to do and anything else would be impractical ("practicalness"), and the chosen action is precisely what it is, nothing more and nothing less ("thinness").

Common sense and intuition arise from pattern recognition or the unconscious cognitive matching of a particular pattern with similar patterns in a larger reservoir of patterns that has been built up through experience [29]. Experience therefore strengthens the confidence that practitioners have in their intuitions [30]. Intuitive knowledge also appears to be more acute among experts as expertise requires the integration of factual and procedural knowledge:

The sense of "owning" a technique comes after the integration of procedural knowledge of performing or doing it and propositional knowledge of the facts and theory behind the technique; and both exploration and practice are necessary for the integration [15, p. 495].

A similar perspective on the development of expertise that also points to an integration of factual and procedural knowledge is the stage model by Dreyfus and Dreyfus [31], which Benner [32] subsequently applied to clinical nursing practice. According to this model, expertise is developed through a process of skills acquisition, from the initial conscious application of rule-guided know-that to the eventual automation of experiencebased know-how that has become fully internalised.

\section{Unpacking personal knowledge}

Although personal knowledge is discussed here as a separate concept, it is in fact a broader category of knowledge that includes both factual and procedural knowledge. According to Jones [33], knowledge can be personal in six senses, each is expressed in relation to "me": (i) owned by me; (ii) experienced by me; (iii) directed towards me; (iv) relevant to me; (v) about me; or (vi) transmitted by me. Arguably, the first two meanings, ownership and experience, also provide the best description for personal knowledge - i.e. knowledge that is owned by the practitioner as it is part of the internal knowledge store, and largely incorporates first-hand experience. In addition, a practitioner's personal knowledge store also incorporates any external information that was directed to the practitioner and of which the practitioner has stored a memory, either consciously or subconsciously. This particularly applies to information that was perceived as relevant at the time of encounter. The practitioner may also extract parts of the store of personal knowledge to transmit to others.

Personal knowledge thus develops not only because of multiple experiences, involving both failures and successes, but also because of encounters with different sources of external information (e.g. early training materials, practice guidelines and fellow practitioners). Any claim made by an external source can be of three types. Firstly, it can represent factual knowledge, which refers to instances where the scientific method was used to produce the claim, resulting in a claim that is backed by the best of available scientific evidence. Secondly, a claim can be labelled as opinion/belief if available scientific evidence does not provide any support for that claim or contradicts it. Thirdly, between these two extremes (factual knowledge and opinion/belief) one finds the grey category of "potential 
factual knowledge", referring to claims of uncertain nature. Such claims can be either factually-based or opinion-based but a final decision is lacking for two reasons. Either the claim has not yet been subjected to the scientific method, or relevant scientific research has been conducted by other parties, mostly for unrelated reasons, but the findings are sitting unobtrusively in the world's vast pool of documented scientific research findings.

Deeply embedded within a practitioner's store of personal knowledge is what is referred to as procedural knowledge. It is an intimate and automated expression of personal knowledge, representing that part of personal knowledge which is internalised and habitually performed in practice. Intuition, common sense and gut feelings all point to the presence of internalised procedural knowledge. However, although procedural knowledge operates instinctively and subconsciously, not all procedural knowledge remains subconscious. Some parts can be vocalized, and thus codified, if the practitioner is asked to reflect upon the procedure concerned and formulate an explanation. That being said, some parts of procedural knowledge - called tacit knowledge - will always elude codification. All of the above insights are captured in figure 1, which provides a visual representation of a practitioner's knowledge store.

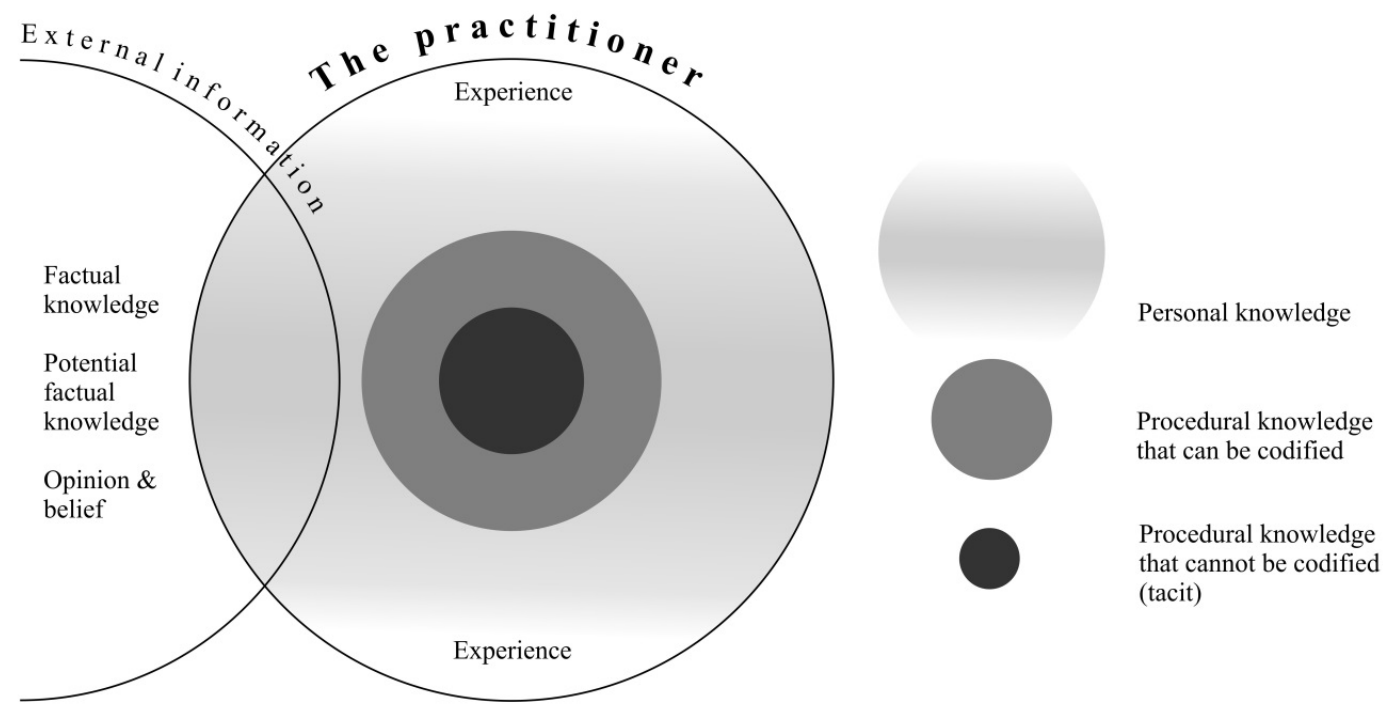

Figure 1. Visual Representation of a Practitioner's Knowledge Store.

Note: a knowledge store can be defined as a dense set of personal knowledge made up of procedural knowledge (parts of which are tacit), factual knowledge, potential factual knowledge and opinions/beliefs; the totality of which is continuously refined and expanded through experience and external information picked up from people, documents or events. 
In some instances, then, procedural knowledge cannot be made explicit and documented as it is inherently tacit. In other instances the implicitness of procedural knowledge can also be made explicit, i.e. the underlying rules can be extracted through reflection, communication, etcetera, and presented as propositions [22, 34]. These propositions can then be classified as factual knowledge, potential factual knowledge or mere opinions/beliefs, depending on the degree of availability of scientific research findings to support the proposition. However, any attempt at codification is a matter of choice, and needs to take into consideration both the benefit and cost involved in codification.

\section{Linking a practitioner's knowledge store with evidence-based practice (EBP), "mindlines" and a "knowledge network"}

The prioritization of propositions based on quality science - called factual knowledge in this paper - is especially evident in the present push for EBP. Part of the EBP objective is to strengthen the scientific base of practitioners' decision-making and reduce their reliance on opinion-based decisions [35]. In health, for instance, EBP aims to achieve this by facilitating the uptake of claims that are science-based and which have been "appraised and found to be of sufficient rigour" [36, p. 270], specifically claims derived from "high quality epidemiological studies, clinical intervention trials, and other robust research designs on human subjects" (p. 397) (Sackett et al., cited in [37]). Promising instruments in this regard are the so-called "third-generation" knowledge products [12], of which practice guidelines are key examples. The latter are user-friendly practice recommendations derived from systematic reviews and meta-analyses of individual research studies. However, practice guidelines, as carriers of factual knowledge, are sometimes overlooked by health practitioners in their daily routines. For instance, an ethnographic study of clinicians in two general practices in the U.K. [38] revealed a stronger reliance on knowledge conveyed through networks with other practitioners and professionals, without the clinicians questioning whether or not the views of others were rooted in scientific research (i.e. factual or not). The overwhelming tacit dimension of the clinicians' knowledge base compelled the investigators to introduce the notion of "mindlines":

... clinicians relied on what we have called "mindlines", collectively reinforced, internalised tacit guidelines, which were informed by brief reading, but mainly by their interactions with each other and with opinion leaders, patients, and pharmaceutical representatives and by other sources of largely tacit knowledge that built on their early training and their own and their colleagues' experience [38, p. 1014].

The point to be made is that the description of "mindlines" is reconcilable with the representation of the knowledge store of practitioners (see the note to figure 1). The conception of the knowledge store of practitioners also conforms well to the idea of a "knowledge network" by Stolper et al. [39]. These authors portrayed the medical knowledge of general practitioners as an associative network of inter-connective knowledge parts that involve high-level concepts, contextual factors, patient information, symptoms, 
treatments, drugs, etc. The richer and denser the network becomes in terms of experience, the more automated and non-analytical the process of clinical reasoning also becomes, thereby sparking regular instances of gut feeling and intuitive knowing:

With increasing experience, their [general practitioners - GPs] knowledge network will become richer and more coherent, and non-analytical reasoning will more often be invoked, but experienced GPs are able to switch to analytical reasoning when the automatic approach is not enough to explain the patient's situation (pp. 200201) [39].

Lastly, since factual knowledge (according to figure 1) also provides an input to the dense knowledge network or personal knowledge store of practitioners, it is not illogical to argue that intuitive knowing could very well have an underlying scientific base, a point that is also echoed by others [40].

\section{Do science-based practitioners prioritize non-scientific knowledge over scientific knowledge?}

This section addresses the question whether it can be claimed that science-based practitioners prioritize non-scientific knowledge over scientific knowledge in certain instances. A four-fold taxonomy of practice knowledge by Estabrooks et al. [41] provides an introduction to this discussion. Estabrooks and colleagues classified the knowledge of nurses into four categories: social interactions, experiential knowledge, documents and a priori knowledge. Social interactions refer to the processes of communication, information exchange and relationship formation among nurses, and also between nurses and other health care professionals, patients and their families. These are either informal (spontaneous interactions) or formal (structured according to time and place, e.g. conferences, short courses and ward rounds). Experiential knowledge is gained through practice observations. Documents can be either unit-based (patient charts, treatment protocols, etc.) or off-unit (journals, research reports, etc.). A priori knowledge refers to intrinsic knowledge that nurses bring with them to their unit, which includes the knowledge they acquired at nursing school, their personal beliefs and common sense.

Estabrooks and colleagues [41] found that social interactions were the most important source of information, followed by experiential knowledge. According to the authors, it is not uncommon for experiential knowledge and documented knowledge to compete directly, especially in instances where documentary evidence (in journals, protocols, etc.) requires a change of practice where the practitioner's experiential knowledge suggests otherwise. This often results in the nurses not implementing the documentary evidence. However, I would argue that such scenarios do not mean that practitioners prioritize non-science over science in their decision-making. Experiential knowledge and a priori knowledge are illustrative of embodied, non-propositional knowledge but, as stated elsewhere, it does not mean that parts of these cannot ultimately be formulated as verbal rules (propositions), documented, and subjected to public scrutiny. In instances where 
such verbal rules can be extracted and their scientific backing demonstrated, the extracted rules would qualify as facts. A potential factual base is thus always lurking in the background, which could turn out to be either rooted in valid evidence or simply a mistaken hypothesis. However, the final verdict requires human intervention: someone has to link the knowledge claims to existing scientific evidence or initiate new research into the validity of the claims. Similarly, what Estabrooks et al. refer to as documents are carriers of codified propositions. Given the diversity of documents that are available in practice settings, the propositions conveyed by these documents may or may not be factual, again depending on the degree of supporting scientific evidence. Lastly, formal and informal social interactions typically involve the exchange of propositions, and again it could be established whether these are based on scientific evidence once the propositions have been documented.

The same reasoning applies to my own work on the information sources of winemakers. Elsewhere in this journal [8] I discussed the information sources that South African winemakers most frequently consult, but the focus now is on the extent to which the same group of winemakers regard a selection of these sources as extremely important for their winemaking practice. As can be seen in table 1, considerable importance is attached to experience and personal knowledge. Again, it needs to be emphasized that although they place significantly higher value on experience, personal knowledge and informal social interactions (compared with various explicit sources of scientific research findings), this does not necessarily mean that winemakers prioritize non-scientific knowledge over scientific knowledge. Should the rules of knowing that underlie both experiential and personal knowledge be made explicit and thus public (provided that the knowledge is not tacit), a factual evidence base may or may not emerge if the rules are linked to new or existing scientific evidence.

Moreover, it needs to be remembered that the scientific method is a tool that draws "on independent realities to evaluate claims rather than depending on reason alone" [42, p. 7]. It is characterised by a special form of reasoning, namely empirical reasoning, which implies systematic observation and measurement. Kuhn [43], for instance, argued that scientific thinking is not "a technical, rarefied form of thought, accessible and relevant only to specialists trained in its use" (p. 261). By referring to a series of exercises, Kuhn illustrated that argumentative reasoning (e.g. if X, then $\mathrm{Y}$, and if not X, then not $\mathrm{Y}$ ), which at times underlies conscious and reflective thinking in everyday practice, could also be seen to resemble the kind of good thinking found in the scientific method. Thus, not only scientists can apply empirical reasoning (i.e. theorization combined with experimentation and systematic observation) to arrive at factual claims. Hence, knowledge derived from experience may also be considered factual at times. However, in order for such knowledge to earn the label of "scientific" it needs to be properly documented for it to be validated (e.g. through replication studies or peer review), as science is essentially a public endeavour. 
Table 1. Extent to which South African Winemakers regarded Information Sources as Extremely Important for their Winemaking.

\begin{tabular}{|l|c|c|c|}
\hline & \multirow{2}{*}{$\begin{array}{c}\text { Percentage } \\
\text { extremely } \\
\text { Information source }\end{array}$} & \multicolumn{2}{|c|}{$\begin{array}{c}\text { Classification of information source } \\
\text { in terms of: }\end{array}$} \\
\cline { 3 - 4 } & $\begin{array}{c}\text { Knowledge claims } \\
\text { that it contains }\end{array}$ & $\begin{array}{c}\text { Source category } \\
\text { (Estabrooks et al. [41]) }\end{array}$ \\
\hline $\begin{array}{l}\text { Own experience (what has worked/ } \\
\text { not worked before) (N=211) }\end{array}$ & $76 \%$ & $\begin{array}{c}\text { Factual/ potential } \\
\text { factual/ belief }\end{array}$ & Experiential \\
\hline $\begin{array}{l}\text { Results of wine analyses from wine } \\
\text { laboratories (N=211) }\end{array}$ & $76 \%$ & Factual & Documents \\
\hline $\begin{array}{l}\text { Personal knowledge/ intuition/ com- } \\
\text { mon sense (N=210) }\end{array}$ & $74 \%$ & $\begin{array}{c}\text { Factual/ potential } \\
\text { factual/ belief }\end{array}$ & A priori* \\
\hline $\begin{array}{l}\text { Staff or colleagues at your cellar/ } \\
\text { winery/ estate (N=207) }\end{array}$ & $58 \%$ & $\begin{array}{c}\text { Factual/ potential } \\
\text { factual/ belief }\end{array}$ & $\begin{array}{c}\text { Social interactions: } \\
\text { informal }\end{array}$ \\
\hline $\begin{array}{l}\text { South African winemakers in other } \\
\text { cellars/ wineries/ estates (N=209) }\end{array}$ & $57 \%$ & $\begin{array}{c}\text { Factual/ potential } \\
\text { factual/ belief }\end{array}$ & $\begin{array}{c}\text { Social interactions: } \\
\text { informal }\end{array}$ \\
\hline $\begin{array}{l}\text { Formal training received at college/ } \\
\text { university (N=210) }\end{array}$ & $50 \%$ & Factual & $\begin{array}{c}\text { Social interactions: } \\
\text { formal }\end{array}$ \\
\hline $\begin{array}{l}\text { Textbooks and manuals of winemak- } \\
\text { ing (N=209) }\end{array}$ & $45 \%$ & Factual & \begin{tabular}{c} 
Documents \\
\hline $\begin{array}{l}\text { Information sessions/ seminars/ } \\
\text { workshops for the South African } \\
\text { wine industry (N=208) }\end{array}$
\end{tabular} \\
\hline $\begin{array}{l}\text { \# Wynboer in the WineLand magazine } \\
\text { (N=211) }\end{array}$ & $15 \%$ & Factual & $\begin{array}{c}\text { Social interactions: } \\
\text { formal }\end{array}$ \\
\hline $\begin{array}{l}\text { \# South African Journal of Enology } \\
\text { and Viticulture (N=209) }\end{array}$ & $9 \%$ & Factual & Documents \\
\hline
\end{tabular}

\# See Boshoff [8, p. 8] for a description of these two information sources; the survey methodology which generated the above results - is also described in that paper.

* I am using the notion of a priori knowledge here to be consistent with the taxonomy by Estabrooks et al. [41]. However, based on the portrayal of a practitioner's knowledge store in figure 1, it is more correct to say that "personal knowledge/ intuition/ common sense" is informed by not only a priori knowledge but also by knowledge from all the other source categories (experience, social interactions and documents).

\section{Concluding comments}

Future studies on the social dynamics of knowledge could benefit from the theoretical frame provided in this paper, especially studies on the knowledge of professionals who fall into the first category of science-based practitioners, as explained in the introduction (i.e. those whose practices are informed by the outputs of science). Relevant questions for empirical investigation include the following: under what conditions are the personal knowledge and experiences of science-based practitioners (and others) prioritized over scientific knowledge, and to what extent and how can their personal and experiential knowledge be documented and its factuality demonstrated? These are topics for mostly qualitative (but also quantitative) enquiry that could be of interest to scholars in science communication and knowledge utilisation, given that science communication - as an 
interdisciplinary field of study — is also concerned with "whose truth most matters in society" [11, p. 2]. It also calls for critical engagement with social constructivist theories of learning [44]. In fact, the social constructivist take on learning theory is precisely what has been highlighted here, namely that external information (e.g. a particular research finding) is assessed in the light of existing personal knowledge and experiences, and on the basis of that interaction new knowledge gets constructed. Moreover, studies on the social dynamics of knowledge in different practice contexts, and specifically how these affect science communication efforts and research uptake, also have the potential of broadening the types of research methods that are currently favoured in science communication research. By proposing more ethnographic case studies on the "knowledge" component of knowledge utilisation, and even theory-building studies, a reply could be formulated in response to Borchelt's question [45] as to whether there is life beyond the current emphasis on content analysis and attitude surveys as research methods in science communication.

The notion of a knowledge store, and the various associated concepts of knowledge, could also add to the wider discussion on scientific expertise. The integration of factual and procedural knowledge, as well as instances of common sense and intuitive knowing that are informed by a rich network of knowledge and experience, are all "hallmarks" of experts. Both categories of science-based practitioners (e.g. both the university professor in oenology who produces science and the winemaker at the family estate whose practice is informed by the outputs of science) can be regarded as what Collins and Evans [46] described as "contributory experts", as each would have sufficient expertise to contribute to the science of the topic in question (winemaking). According to these authors:

it is more difficult to separate the credentialed scientist from the experienced practitioner than was once thought: when we move toward experience as a criterion of expertise the boundary around science softens, and the set of activities known as 'science' merges into expertise in general [46, p. 253].

However, having contributory expertise does not necessarily imply the presence of interactional expertise as well. The latter entails having enough expertise to interact with and absorb the contributory expertise of the other [46]. My take on the matter is that science communicators - as professional specialists - are intermediaries trying to compensate for the lack of interactional expertise of scientists through "the use of appropriate skills, media, activities, and dialogue" to produce the outcomes of "awareness, enjoyment, interest, opinion-forming, and understanding" [47, p. 183]. However, what intermediaries currently compensate for the lack of interactional expertise of the contributing experts in the practice domain in order for these experts' claims to be valued by scientists? The question is relevant in the light of a previous comment that not only scientists but also practitioners in everyday settings can apply the principles of the scientific method to arrive at factual claims. Moreover, what kind of scientific knowledge should science communicators be concerned with as part of their professional activities? Should this be only knowledge generated by the scientific method at scientific institutions by those with the necessary credentials? Or should the activities of science communicators expand 
to include knowledge that is generated through the application of the scientific method in experienced-based practice? Or what about potential factual and procedural knowledge that is embodied in a practitioner's "knowledge store", which needs to be extracted, documented and communicated to scientists so that the knowledge claims become public and can be tested and verified? Should that also be part of science communication as a professional specialisation? The many questions beg for debate and response.

\section{References}

[1] A. Cherney, B. Head, P. Boreham, J. Povey and M. Ferguson (2013), "Research utilization in the social sciences: a comparison of five academic disciplines in Australia", Sci. Commun. 35: 780-809.

[2] B.I. Crona and J.N. Parker (2011), "Network determinants of knowledge utilization: preliminary lessons from a boundary organization", Sci. Commun. 33: 448-471.

[3] N. Jacobson (2007), "Social epistemology — theory for the 'fourth wave' of knowledge transfer and exchange research", Sci. Commun. 29: 116-127.

[4] O. Belkhodja, N. Amara, R. Landry and M. Ouimet (2007), "The extent and organizational determinants of research utilization in Canadian health services organizations", Sci. Commun. 28: 377-417.

[5] N. Amara, M. Ouimet and R. Landry (2004), "New evidence on instrumental, conceptual, and symbolic utilization of university research in government agencies", Sci. Commun. 26: 75-106.

[6] D.M. Kramer and D.C. Cole (2003), "Sustained, intensive engagement to promote health and safety knowledge transfer to and utilization by workplaces", Sci. Commun. 25: 56-82.

[7] R. Landry, N. Amara and M. Lamari (2001), "Climbing the ladder of research utilization: evidence from social science research", Sci. Commun. 22: 396-422.

[8] N. Boshoff (2014), "Use of scientific research by South African winemakers", JCOM 13(01): A01, retrieved 18 June 2014.

[9] S. Tveden-Nyborg, M. Misfeldt and B. Boelt (2012), "Scientific knowledge dissemination in Danish seed communities of practice", JCOM 11(03): A02, retrieved 18 June 2014.

[10] M.J. Carneiro and T. da-Silva-Rosa (2011), "The use of scientific knowledge in the decision making process of environmental public policies in Brazil", JCOM 10(01): A03, retrieved 18 June 2014.

[11] S.H. Priest (2010), "Coming of age in the academy? The status of our emerging field", JCOM 09(03): C06, retrieved 18 June 2014.

[12] I.D. Graham, J. Logan, M.B. Harrison, S.E. Straus, J. Tetroe, W. Caswell and N. Robinson (2006), "Lost in knowledge translation: time for a map?", J. Contin. Educ. Health. Prof. 26: 13-24.

[13] G. Ryle (1949), The concept of mind, Hutchinson, London, U.K. .

[14] G. Ryle (1971), "Knowing how and knowing that", in Collected papers: Volume II of collected essays, 1929-1968, Hutchinson \& Co, London, U.K. .

[15] B. Sahdra and P. Thagard (2003), "Procedural knowledge in molecular biology", Philos. Psychol. 16: $477-498$.

[16] D. Pears (1971), What is knowledge?, George Allen \& Unwin Ltd, London, U.K. .

[17] J. Rycroft-Malone, K. Seers, A. Titchen, G. Harvey, A. Kitson and B. McCormack (2004), "What counts as evidence in evidence-based practice?", J. Adv. Nurs. 47: 81-90.

[18] D. O'Brien (2006), An introduction to the theory of knowledge, Polity Press, Cambridge, U.K. .

[19] S. Haack (1993), Evidence and inquiry: towards reconstruction in epistemology, Blackwell Publishers, Malden, U.S.A. 
[20] CHSRF (2005), Conceptualizing and combining evidence for health system guidance, Canadian Health Services Research Foundation, Ottawa, Canada.

[21] P. Thagard (2006), "How to collaborate: procedural knowledge in the cooperative development of science", Southern J. Philos. XLN: 177-196.

[22] H. Taylor (2005), "A critical decision interview approach to capturing tacit knowledge: principles and application", Int. J. Knowl. Manage. 1: 25-39.

[23] M. Polanyi (1966), The tacit dimension, Doubleday, New York, U.S.A. .

[24] P. Nilsen, K. Roback, A. Broström and P.-E. Ellström (2012), "Creatures of habit: accounting for the role of habit in implementation research on clinical behaviour change", Implement. Sci. 7: 53.

[25] B.A. Carper (1978), "Fundamental patterns of knowing in nursing", Adv. Nurs. Sci. 1: 13-23.

[26] B. McCormack (1992), "Intuition: concept analysis and application to curriculum development. I. Concept analysis", J. Clin. Nurs. 1: 339-344.

[27] E. Stolper, M. van Bokhoven, P. Houben, P. van Royen, M. van de Wiel, T. van der Weijden and G.J. Dinant (2009), "The diagnostic role of gut feelings in general practice: a focus group study of the concept and its determinants", BMC Fam. Pract. 10: 17.

[28] C. Geertz (1983), Local knowledge: further essays in interpretive anthropology, Basic Books, New York, U.S.A. .

[29] G. Norman, M. Young and L. Brooks (2007), "Non-analytical models of clinical reasoning: the role of experience", Med. Educ. 41: 1140-1145.

[30] L. Chaffy, C. Unsworth and E. Fossey (2010), “A grounded theory of intuition among occupational therapists in mental health practice", Brit. J. Occup. Ther. 73: 300-308.

[31] H.L. Dreyfus and S.E. Dreyfus (1986), Mind over machine: The power of human intuition and expertise in the era of the computer, The Free Press, New York, U.S.A. .

[32] P. Benner (1984), From novice to expert: excellence and power in clinical nursing practice, Addison-Wesley Publishing Company, Menlo Park, U.S.A.

[33] W. Jones (2011), "No knowledge but through information”, in D.J. Pauleen and G.E. Gorman eds., Personal knowledge management, Gower Publishing, Farnham, U.K. .

[34] V. Ambrosini and C. Bowman (2001), "Tacit knowledge: some suggestions for operationalization", J. Manage. Stud. 38: 811-829.

[35] S. Timmermans and E.S. Kolker (2004), "Evidence-based medicine and the reconfiguration of medical knowledge", J. Health. Soc. Behav. 45: 177-193.

[36] K. Bannigan and R. Bryar (2002), "The importance of overcoming barriers to research utilization”, Brit. J. Ther. Rehabil. 9: 270-273.

[37] T. Greenhalgh (2002), "Intuition and evidence - uneasy bedfellows?", Brit. J. Gen. Prac. 52: 395-400.

[38] J. Gabbay and A. le May (2004), "Evidence based guidelines or collectively constructed 'mindlines'? Ethnographic study of knowledge management in primary care”, Brit. Med. J. 329: 1013-1016.

[39] E. Stolper, M. van de Wiel, P. van Royen, M. van Bokhoven, T. van der Weijden and G.J. Dinant (2010), "Gut feelings as a third track in general practitioners' diagnostic reasoning", J. Gen. Intern. Med. 96: 197-203.

[40] I. Welsh and C.M. Lyons (2001), "Evidence-based care and the case for intuition and tacit knowledge in clinical assessment and decision making in mental health nursing practice: an empirical contribution to the debate", J Psychiatr. Ment. Hlt. 8: 299-305.

[41] C.A. Estabrooks, W. Rutakumwa, K.A. O’Leary, J. Profetto-McGrath, M. Milner, M.J. Levers and S. Scott-Findlay (2005), "Sources of practice knowledge among nurses", Qual. Health Res. 15(4): $460-476$. 
[42] R.L. Rosnow and R. Rosenthal (1996), Beginning behavioural research: a conceptual primer, 2nd ed., Prentice-Hall, Englewood Cliffs, U.S.A.

[43] D. Kuhn (1996), "Is good thinking scientific thinking?", in D.R. Olson and N. Torrance eds., Modes of thought: explorations in culture and cognition, Cambridge University Press, Cambridge, U.K. .

[44] A. Thomas, A. Menon, J. Boruff, A. Rodriguez and S. Ahmed (2014), “Applications of social constructivist learning theories in knowledge translation for healthcare professionals: a scoping review”, Implement. Sci. 9:54.

[45] R. Borchelt (2012), "The science communication literature research project. Looking back at a decade of PCST research, 2000-2009”, paper presented at the 12th International Public Communication of Science and Technology Conference, Florence, Italy, 18-20 April 2012.

[46] H.M. Collins and R. Evans (2002), "The third wave of science studies: studies of expertise and experience", Soc. Stud. Sci. 32(2): 235-296.

[47] T.W. Burns, D.J. O’Connor and S.M. Stocklmayer (2003), "Science communication: a contemporary definition”, Pub. Underst. Sci. 12: 183-202.

\section{Author}

Nelius Boshoff $(\mathrm{PhD})$ is a Senior Lecturer at the Centre for Research on Evaluation, Science and Technology (CREST) at Stellenbosch University, South Africa, host of the DSTNRF Centre of Excellence in Scientometrics and STI Policy. His professional interests include studies of knowledge uptake, research impact and research collaboration, as well as bibliometrics with a focus on Africa. E-mail: scb@sun.ac.za.

How to CITE: N. Boshoff, "Types of knowledge in science-based practices", JCOM 13(03)(2014)A06. 